\title{
Atypical Manifestations of Cat-Scratch Disease, United States, 2005-2014
}

\author{
Courtney C. Nawrocki, Ryan J. Max, ${ }^{1}$ Natalie S. Marzec, ${ }^{2}$ Christina A. Nelson
}

\section{Medscape ACTIVITY}

In support of improving patient care, this activity has been planned and implemented by Medscape, LLC and Emerging Infectious Diseases. Medscape, LLC is jointly accredited by the Accreditation Council for Continuing Medical Education (ACCME), the Accreditation Council for Pharmacy Education (ACPE), and the American Nurses Credentialing Center (ANCC), to provide continuing education for the healthcare team.

Medscape, LLC designates this Journal-based CME activity for a maximum of 1.00 AMA PRA Category 1 Credit(s) ${ }^{\mathrm{TM}}$. Physicians should claim only the credit commensurate with the extent of their participation in the activity.

Successful completion of this CME activity, which includes participation in the evaluation component, enables the participant to earn up to $1.0 \mathrm{MOC}$ points in the American Board of Internal Medicine's (ABIM) Maintenance of Certification (MOC) program. Participants will earn MOC points equivalent to the amount of $\mathrm{CME}$ credits claimed for the activity. It is the CME activity provider's responsibility to submit participant completion information to ACCME for the purpose of granting ABIM MOC credit.

All other clinicians completing this activity will be issued a certificate of participation. To participate in this journal CME activity: (1) review the learning objectives and author disclosures; (2) study the education content; (3) take the post-test with a $75 \%$ minimum passing score and complete the evaluation at http://www.medscape.org/journal/eid; and (4) view/print certificate. For CME questions, see page 1644 .

Release date: June 17, 2020; Expiration date: June 17, 2021

\section{Learning Objectives}

Upon completion of this activity, participants will be able to:

- $\quad$ Assess the epidemiology of atypical CSD in the United States, based on an analysis of data from the 2005 to 2014 MarketScan national health insurance claims databases

- Describe the clinical features of atypical CSD in the United States, based on an analysis of data from the 2005 to 2014 MarketScan national health insurance claims databases

- Describe the clinical and public health implications of the epidemiology and clinical features of atypical CSD in the United States, based on an analysis of data from the 2005 to 2014 MarketScan national health insurance claims databases

\section{CME Editor}

Thomas J. Gryczan, MS, Technical Writer/Editor, Emerging Infectious Diseases. Disclosure: Thomas J. Gryczan, MS, has disclosed no relevant financial relationships.

\section{CME Author}

Laurie Barclay, MD, freelance writer and reviewer, Medscape, LLC. Disclosure: Laurie Barclay, MD, has disclosed no relevant financial relationships.

\section{Authors}

Disclosures: Courtney C. Nawrocki, MPH; Natalie S. Marzec, MD, MPH; and Christina A. Nelson, MD, MPH, have disclosed no relevant financial relationships. Ryan J. Max, $\mathbf{M S P H}$, has disclosed the following relevant financial relationships: employed by a commercial interest: GlaxoSmithKline.

Author affiliations: Oak Ridge Institute for Science and Education, Oak Ridge, Tennessee, USA (C.C. Nawrocki, R.J. Max); Centers for Disease Control and Prevention, Fort Collins, Colorado, USA (C.C. Nawrocki, R.J. Max, C.A. Nelson); University of Colorado, Aurora, Colorado, USA (N.S. Marzec)
${ }^{1}$ Current affiliation: University of North Carolina, Chapel Hill, North Carolina, USA.

${ }^{2}$ Current affiliation: Colorado Department of Public Health and Environment, Denver, Colorado, USA. 
Atypical manifestations that can be severe and difficult to diagnosis develop in $5 \%-20 \%$ of patients with catscratch disease. To clarify the epidemiology of atypical cat-scratch disease in the United States, we analyzed data from the 2005-2014 MarketScan national health insurance claims databases by using the International Classification of Diseases, 9th Revision, Clinical Modification, codes for cat-scratch disease and selected atypical manifestations: retinitis/neuroretinitis, conjunctivitis, neuritis, encephalitis, hepatosplenic disease, osteomyelitis, erythema nodosum, and endocarditis. Atypical cat-scratch disease accounted for $1.5 \%$ of all cases, resulting in an average annual incidence of 0.7 cases $/ 100,000$ population. Atypical cat-scratch disease was associated with increased risk for hospitalization (risk ratios $8.77,95 \% \mathrm{Cl} 6.56-11.72$ ) and occurred most often in female patients 10-14 years of age. Ocular $(48.7 \%)$, hepatosplenic $(24.6 \%)$, and neurologic (13.8\%) manifestations were most common among patients. A more comprehensive understanding of atypical cat-scratch disease can improve patient diagnosis and potentially elucidate pathophysiology of the disease.

C at-scratch disease, a zoonotic bacterial infection, occurs worldwide and is caused by Bartonella henselae, a fastidious, intracellular gram-negative bacillus (1). Cats are the major reservoir of $B$. henselae and are infected by Ctenocephalides felis cat fleas. Although most cats infected with $B$. henselae are asymptomatic, signs such as fever and myocarditis might develop in some cats $(2,3)$. Humans usually become infected through the scratches or bites of infected cats. $B$. henselae has also been shown to infect dogs (4), in some cases resulting in canine endocarditis (5-7). Although some human cases of cat-scratch disease have been linked to canine-human transmission (8-12), further research is needed to clarify the public health significance of $B$. henselae infection in dogs.

The true burden of cat-scratch disease in the United States is unknown because it is not a reportable condition; however, efforts have been made to estimate its incidence in the United States. In 1993, an analysis of hospital discharge data estimated a nationwide incidence of hospitalized cases of 0.77 0.86 cases $/ 100,000$ population annually (13). A subsequent study that examined a database of national health insurance claims during 2005-2013 found that incidence of cat-scratch disease in the United States was highest in southern states (6.4 cases/100,000 population) and in children 5-9 years of age (9.4 cases/100,000 population) (14).

Cat-scratch disease typically manifests as fever and an erythematous papule at the site of the cat scratch or bite, followed by lymphadenopathy in the regional lymph nodes that drain the area of inoculation (15). The papule usually appears 3-10 days after inoculation and can persist for several weeks, with regional lymphadenopathy developing 1-3 weeks postinoculation (1). From $80 \%$ to $95 \%$ of cases of catscratch disease are consistent with this typical presentation, and the remainder of cases manifest as atypical and more severe symptoms $(16,17)$.

Atypical manifestations of cat-scratch disease can involve the eyes, nervous system, heart, liver, spleen, skin, or musculoskeletal system and might result in major illness $(1,15)$. When cat-scratch disease involves the eye, the anterior compartment might be affected by Parinaud oculoglandular syndrome, and the posterior compartment might be affected by retinitis, retinochoroiditis, optic neuritis, uveitis, and vitritis (18-20). Nervous system involvement most commonly manifests as encephalopathy, but seizures, nerve palsies, neuritis, myelitis, and cerebellar ataxia have also been reported $(21,22)$.

Endocarditis is more often seen in adults with cat-scratch disease than in children, although preexisting valvular disease puts children at increased risk for this complication (1). Bartonella infection can also cause abdominal pain and microabscesses in the liver and spleen (23), and in immunocompromised hosts can result in bacillary peliosis hepatis (24). In addition to the classic erythematous papule at the site of inoculation, erythema nodosum and bacillary angiomatosis are reported dermatologic manifestations of atypical infection $(25,26)$. Osteolytic lesions, osteomyelitis, and arthritis have also been associated with cat-scratch disease $(16,24,26)$. A study in 1998 found cat-scratch disease to be the third leading cause of prolonged fever of unknown origin in children, and a history of cat exposure was frequently absent (27).

Atypical manifestations of $B$. henselae infection can be severe, difficult to diagnose, and lead to lasting impairment. It is unclear why certain patients develop atypical cat-scratch disease, and little is known about its epidemiology. Improved understanding of atypical cat-scratch disease could lead to better recognition of cases by clinicians and inform efforts to understand the pathophysiology of this disease. The purpose of this study was to better characterize the rare and serious complications of this nonreportable zoonotic infection by using nationwide insurance claims data.

\section{Methods}

To identify potential cases of atypical cat-scratch disease, we conducted a retrospective analysis of 
persons enrolled in the Truven Health MarketScan Commercial Claims and Encounters Database (Truven Health Analytics, https:/ / www.ibm.com) during 2005-2014. The MarketScan Commercial Claims and Encounters Database includes persons <65 years of age covered by select employer-sponsored health insurance plans in all 50 states and contains administrative claims data on outpatient visits, inpatient admissions, and emergency department visits. Demographically, the MarketScan population generally mirrors the US population, with a slight overrepresentation of persons 50-59 years of age and a slight underrepresentation of persons 20-29 years of age (28).

Billing codes from outpatient, inpatient, and emergency department visits are assigned by either a clinician or billing specialist according to the International Classification of Diseases, 9th Revision, Clinical Modification (ICD-9-CM), and procedures are captured as either ICD-9-CM codes, Current Procedure Terminology codes, or Healthcare Common Procedure Coding System codes. Because the International Classification of Diseases, 10th Revision, Clinical Modification, was not officially adopted in the United States until 2015, those codes were not included.

We identified cat-scratch disease cases by extracting all enrollee visit records during the study period with an ICD-9-CM code for cat-scratch disease (078.3). The first instance of a 078.3 diagnosis code in a patient record was considered the index event. Atypical manifestations of interest were selected for analysis if they had recorded precedent in the literature as a complication of cat-scratch disease and distinct, clearly discernable ICD-9-CM codes associated with the specific manifestation. Based on these criteria, the known complications of cat-scratch diseases included for analysis were endocarditis, osteomyelitis, erythema nodosum, conjunctivitis, retinitis/neuroretinitis, encephalitis, neuritis, and hepatosplenic disease.We included ICD-9-CM codes associated with optic neuritis in the retinitis/neuroretinitis category. Encounters with an ICD-9-CM code for cat-scratch disease and an accompanying diagnostic code to indicate the anatomic location of a wound or inoculation site for B. henselae were also flagged for analysis and were categorized as either head or neck region, arm or shoulder region, leg or hip region, or torso region. We compiled a detailed list of all ICD-9-CM codes used to identify atypical manifestations of cat-scratch disease (Appendix Table, https://wwwnc.cdc.gov/ EID/article/26/7/20-0034-App1.pdf).

We extracted insurance billing records of enrollees with ICD-9-CM codes for cat-scratch disease and selected manifestations at either the same encounter or within a 30-day window of one another. These records were evaluated along with previous and subsequent records by 2 independent reviewers (R.J.M. and C.A.N.) to ensure that the clinical picture was consistent with the coded atypical manifestation based on diagnosis codes, procedure codes, and provider types. If plausible alternative causes of the selected manifestation or likely coding errors were identified, we did not include the enrollee record as an atypical case. In cases of discordance, a third reviewer (Paul Mead) determined final categorization based on record review.

We included persons with an ICD-9-CM code for cat-scratch disease but without accompanying atypical manifestation as typical cases for comparison. Residence in a rural area was assigned if an enrollee did not reside in a metropolitan statistical area, as designated by the US Office of Management and Budget. Because previous research has identified increases in cat-scratch disease in late summer, fall, and January $(13,14,29)$, we categorized month of onset as either late summer and fall, January, or all other months for analysis.

We performed descriptive and comparative statistical analyses by using JMP version 13.2.1 (https://www.jmp.com) and SAS version 9.3 (https://www.sas.com). We used Pearson $\chi^{2}$ tests or Fisher exact tests for comparisons of categorical variables. To compare the conditional probability of having atypical cat-scratch disease across strata of potential variables of interest (e.g., sex, age category), we calculated risk ratios (RRs) and associated 95\% CIs. Human subjects review at the Centers for Disease Control and Prevention determined that institutional review board approval was not required for this study.

\section{Results}

\section{Study Population and Incidence}

During 2005-2014, the MarketScan database contained a median of 44,488,485 (range 16,159,068$53,131,420$ ) enrollees each year. Of 14,824 cat-scratch disease cases identified from MarketScan during this period, $224(1.5 \%)$ cases were classified as atypical (Table 1). The average annual incidence of atypical cat-scratch disease diagnoses during the study period was 0.7 cases $/ 100,000$ population.

Atypical cat-scratch disease was most common among adults $15-49$ years of age (47.3\%), and patients with atypical cat-scratch disease were more likely to be hospitalized than those with typical manifestations $(\mathrm{p}<0.0001)$. 
Table 1. Characteristics of patients with cat-scratch disease and risk factors for development of atypical cat-scratch disease, United States, 2005-2014

\begin{tabular}{|c|c|c|c|}
\hline Characteristic & Typical disease, no. (\%), $n=14,600$ & Atypical disease, no. (\%), $\mathrm{n}=224$ & Risk ratio $(95 \% \mathrm{Cl})^{*}$ \\
\hline \multicolumn{4}{|c|}{ ris } \\
\hline M & $5,583(38.2)$ & $94(42.0)$ & $1.17(0.90-1.52)$ \\
\hline $\mathrm{F}$ & $9,017(61.8)$ & $130(58.0)$ & Referent \\
\hline \multicolumn{4}{|l|}{ Age, y } \\
\hline Child $\leq 14$ & $4,678(32.0)$ & $81(36.2)$ & $1.20(0.91-1.57)$ \\
\hline Adult, $15-49$ & $6,421(44.0)$ & $106(47.3)$ & Referent \\
\hline Adult, 50-64 & $3,501(24.0)$ & $37(16.5)$ & $0.63(0.44-0.90)$ \\
\hline \multicolumn{4}{|l|}{ Month of onset } \\
\hline Late summer and fall† & $5,470(37.5)$ & $93(41.5)$ & $1.18(0.90-1.56)$ \\
\hline January & $1,490(10.2)$ & $22(9.8)$ & $1.03(0.65-1.64)$ \\
\hline All other months $\ddagger$ & $7,640(52.3)$ & $109(48.7)$ & Referent \\
\hline Hospitalized & $487(3.3)$ & $56(25)$ & $8.77(6.56-11.72)$ \\
\hline Residence in southern state & $7,732(53.0)$ & $129(57.6)$ & $1.20(0.93-1.57)$ \\
\hline Residence in rural area & $3,235(22.1)$ & $51(22.8)$ & $1.06(0.78-1.45)$ \\
\hline
\end{tabular}

\section{Distribution by Age and Sex}

Children $\leq 14$ years of age accounted for $36.2 \%$ of atypical cat-scratch disease diagnoses overall; 26 cases $(11.4 \%)$ were in female patients $10-14$ years of age (Figure 1). Among female patients 10-14 years of age, 16 patients $(61.5 \%)$ had ocular manifestations (13 retinitis/neuroretinitis and 3 conjunctivitis), and 6 patients $(23.1 \%)$ had hepatosplenic disease.

Nearly half of all patients with atypical catscratch disease were younger adults (15-49 years of age). When we compared older adults with younger adults, older adults (50-64 years of age) had a decreased risk for having atypical cat-scratch disease (RR 0.63, 95\% CI 0.44-0.90) (Table 1).

\section{Seasonality}

Atypical cat-scratch disease diagnoses increased from August through March, and diagnoses were concentrated during August-October (33.5\% of diagnoses) and January-March (29.5\% of diagnoses) (Figure 2), although neither diagnosis in late summer and fall or diagnosis in January were found to be risk factors for development of atypical catscratch disease (Table 1). Trends in atypical catscratch disease diagnoses were similar to trends in typical cat-scratch disease diagnoses. However, typical cat-scratch disease had less defined peak periods, and diagnoses decreased sharply after January.

\section{Geographic Distribution and Residence in Rural Area}

Most $(57.6 \%)$ cases of atypical cat-scratch disease occurred in the southern region of the United States (57.6\%), followed by the midwest $(16.5 \%)$ and northeast $(12.5 \%)$ regions (Figure 3$)$. The geographic distribution of atypical cases did not differ significantly from cases of typical cat-scratch disease.

Residence in a rural area was not a risk factor for development of atypical cat-scratch disease (RR 1.06, 95\% CI 0.78-1.45). Also, the proportion of patients with atypical cat-scratch disease living in a rural area did not differ from the proportion of patients with typical cat-scratch disease living in a rural area $(p=0.70)$.

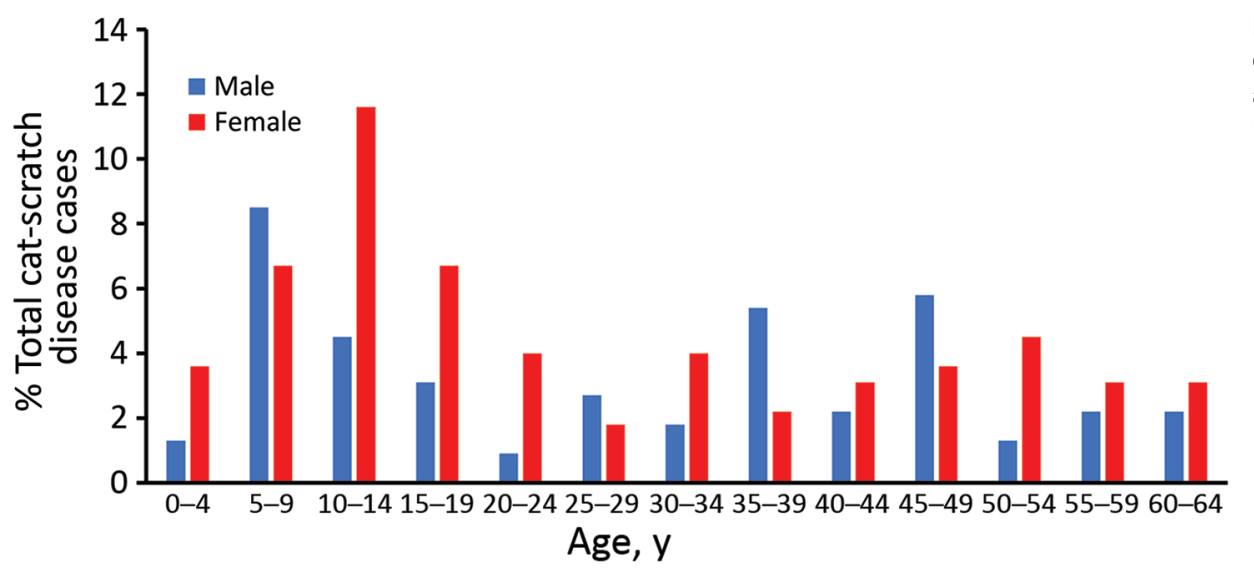

Figure 1. Age and sex distribution of patients with atypical cat-scratch disease, United States, 2005-2014. 


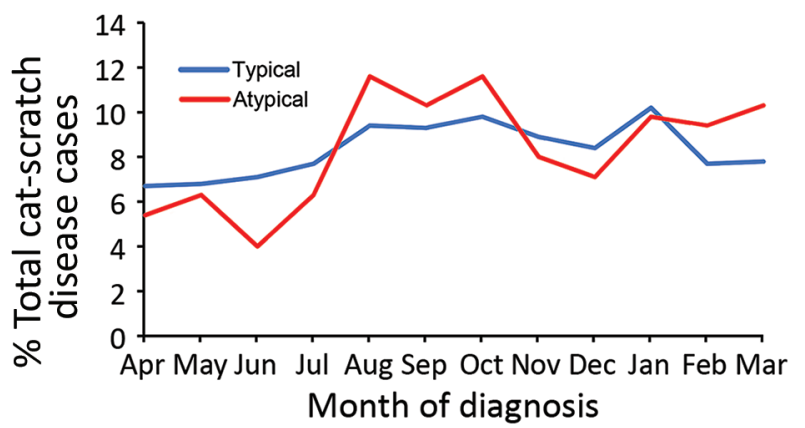

Figure 2. Seasonal variation of atypical and typical cat-scratch disease by month of diagnosis, United States, 2005-2014.

\section{Atypical Manifestations by Type}

Among 224 patients with atypical cat-scratch disease, $109(48.7 \%)$ had ocular manifestations (retinitis/neuroretinitis or conjunctivitis), 55 (24.6\%) had hepatosplenic disease, and $31(13.8 \%)$ had neurologic manifestations (neuritis or encephalitis). The remaining $33(14.7 \%)$ case-patients had osteomyelitis, erythema nodosum, or endocarditis (Table 2). Among patients with ocular manifestations, 82.6\% had retinitis/neuroretinitis; most (64.5\%) patients with neurologic manifestations had encephalitis. Three $(1.3 \%)$ patients with atypical cat-scratch disease had >1 manifestation: 1 patient with osteomyelitis and hepatosplenic disease; 1 patient with endocarditis and hepatosplenic disease; and 1 patient with osteomyelitis, encephalitis, and hepatosplenic disease.

Children $\leq 14$ years of age were at increased risk for hepatosplenic disease (RR 1.76, 95\% CI 1.04-2.99) and osteomyelitis (RR 3.81, 95\% CI 1.28-11.37) compared with persons $\geq 15$ years of age. Older adults (50-64 years of age) were less likely to show development of ocular manifestations (retinitis/neuroretinitis and conjunctivitis) than younger adults (15-49 years of age) (RR 0.49, 95\% CI 0.28-0.85).

Among persons with ocular (retinitis/neuroretinitis and conjunctivitis) manifestations, most diagnoses were made during August-October (31.2\%) and January-March (35.8\%). Among persons with neurologic (neuritis and encephalitis) manifestations, diagnoses were concentrated during October (22.6\%). We observed no notable trends in seasonality of diagnoses for other manifestations of atypical cat-scratch disease (Figure 4). We also observed no differences in geographic distribution or rurality by manifestation of atypical cat-scratch disease.

\section{Hospitalization of Atypical Case-Patients}

Patients with atypical cat-scratch disease were more likely to be hospitalized than patients with typical cat-scratch disease (RR 8.77, 95\% CI 6.56-11.72) (Table 1). Among patients with atypical cat-scratch disease, children $\leq 14$ years of age accounted for $60.7 \%$ of hospitalizations and had an increased risk for hospitalization compared with adults 15-49 years of age (RR 2.34, 95\% CI 1.44-3.79). A total of $57.1 \%$ of the hospitalizations occurred during August-November, and we found an overall increased risk for hospitalization during this period when compared with all other months, except for January (RR 1.88, 95\% CI 1.15-3.05) (Table 3).

Increased risks of hospitalization were found for neurologic manifestations (neuritis and encephalitis) (RR 1.88, 95\% CI 1.15-3.08), hepatosplenic disease (RR 2.30, 95\% CI 1.49-3.55), and osteomyelitis (RR 2.13, 95\% CI 1.20-3.82). Ocular manifestations (retinitis/neuroretinitis and conjunctivitis) were associated with decreased risk for hospitalization (RR $0.23,95 \%$ CI $0.12-0.43$ ).

\section{Location of Wound}

Information on wound location was available for only $10(4.5 \%)$ patients with atypical cat-scratch disease. Among these persons, 2 with conjunctivitis, 1 with encephalitis, and 2 with hepatosplenic disease had a wound on the head or neck; 1 with osteomyelitis and 3 with hepatosplenic manifestations had a wound on the arm or shoulder; 1 with endocarditis had a wound on the leg or hip;

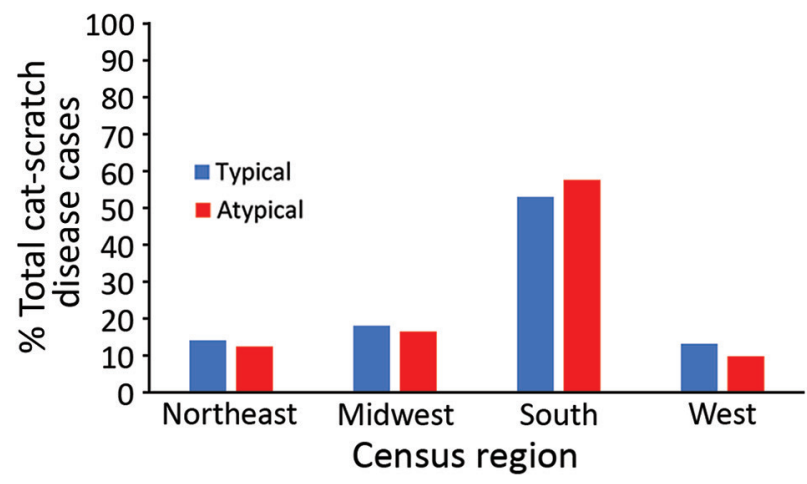

Figure 3. Proportions of typical and atypical cat-scratch disease by US Census region, United States, 2005-2014. Northeast: Connecticut, Maine, Massachusetts, New Hampshire, Rhode Island, Vermont, New Jersey, New York, Pennsylvania. Midwest: Illinois, Indiana, lowa, Kansas, Michigan, Minnesota, Missouri, Nebraska, North Dakota, South Dakota, Ohio, Wisconsin. South: Arkansas, Delaware, Florida, Georgia, Louisiana, Maryland, North Carolina, Oklahoma, South Carolina, Texas, Virginia, West Virginia, Alabama, Hawaii, Kentucky, Mississippi, Oregon, Tennessee. West: Alaska, Arizona, California, Colorado, Idaho, Montana, Nevada, New Mexico, Utah, Washington, Wyoming, Puerto Rico, Virgin Islands. 
Atypical Manifestations of Cat-Scratch Disease

Table 2. Demographic characteristics for patients by manifestation of atypical cat-scratch disease, United States, 2005-2014

\begin{tabular}{|c|c|c|c|c|c|c|c|}
\hline \multirow[b]{2}{*}{ Characteristic } & \multirow[b]{2}{*}{ No. $(\%)$} & \multicolumn{2}{|c|}{ Sex, no. (\%) } & \multicolumn{3}{|c|}{ Age category, y, no. (\%) } & \multirow{2}{*}{$\begin{array}{c}\text { Hospitalized, } \\
\text { no. }(\%)\end{array}$} \\
\hline & & $\mathrm{M}$ & $\mathrm{F}$ & $0-14$ & $15-49$ & $50-64$ & \\
\hline Atypical disease & $224^{*}$ & $94(42.0)$ & $130(58.0)$ & $81(36.2)$ & $106(47.3)$ & $37(16.5)$ & $56(25.0)$ \\
\hline Ocular disease & 109 (48.7) & $46(48.9)$ & $63(48.5)$ & $33(40.7)$ & $60(56.6)$ & $16(43.2)$ & $10(17.9)$ \\
\hline Retinitis/neuroretinitis & $90(40.2)$ & $36(38.3)$ & $54(41.5)$ & $23(28.4)$ & $53(50.0)$ & $14(37.8)$ & $8(14.3)$ \\
\hline Conjunctivitis & $19(8.5)$ & $10(10.6)$ & $9(6.9)$ & $10(12.3)$ & $7(6.6)$ & $2(5.4)$ & $2(3.6)$ \\
\hline Hepatosplenic disease & $55(24.6)$ & $24(25.5)$ & $31(23.8)$ & $25(30.9)$ & $21(19.8)$ & $9(24.3)$ & $24(42.9)$ \\
\hline Neurologic disease & $31(13.8)$ & $13(13.8)$ & $18(13.8)$ & $12(14.8)$ & $13(12.3)$ & $6(16.2)$ & $13(23.2)$ \\
\hline Encephalitis & $20(8.9)$ & $12(12.8)$ & $8(6.2)$ & $12(14.8)$ & $8(7.5)$ & $0(0)$ & $13(23.2)$ \\
\hline Neuritis & $11(4.9)$ & $1(1.1)$ & $10(7.7)$ & $0(0)$ & $5(4.7)$ & $6(16.2)$ & $0(0)$ \\
\hline Osteomyelitis & $14(6.3)$ & $6(6.4)$ & $8(6.2)$ & $9(11.1)$ & $4(3.8)$ & $1(2.7)$ & $7(12.5)$ \\
\hline Erythema nodosum & $11(4.9)$ & $2(2.1)$ & $9(6.9)$ & $4(4.9)$ & $5(4.7)$ & $2(5.4)$ & $4(7.1)$ \\
\hline Endocarditis & $8(3.6)$ & $4(4.3)$ & $4(3.1)$ & $1(1.2)$ & $4(3.8)$ & $3(8.1)$ & $2(3.6)$ \\
\hline
\end{tabular}

and 1 with endocarditis had a wound on an unspecified limb.

\section{Discussion}

Using US nationwide insurance claims data, we identified and characterized 224 atypical cases of cat-scratch disease during 2005-2014 and estimated an average annual incidence of 0.7 cases/100,000 population. Nearly half of all atypical cat-scratch disease cases had ocular manifestations, most of which were retinitis/neuroretinitis. Atypical catscratch disease was most prevalent among female patients 10-14 years of age, who most commonly had ocular manifestations.

Trends in hospitalizations of patients with catscratch disease highlight the severity of atypical catscratch disease compared with typical cat-scratch disease. Atypical cat-scratch disease appears to be particularly severe among children $\leq 14$ years of age, who had an increased risk for hospitalization. Adults 50-64 years of age had the lowest risk for development of atypical cat-scratch disease and specifically ocular manifestations. Reasons that older adults might have complications associated with cat-scratch disease less often than other age groups are unclear and require further study.

Severity of cat-scratch disease in children has been previously documented. In a study conducted by Reynolds et al., $\approx 25 \%$ of hospitalizations of children for cat-scratch disease were caused by complications associated with atypical cat-scratch disease; neurologic and hepatosplenic complications were most common (30). Although children in our study were also particularly at risk for hepatosplenic disease, neurologic and hepatosplenic complications were associated with increased risk for hospitalization in our overall study population, indicating that these manifestations are particularly severe for all age groups. Encephalitis was the most common neurologic manifestation in our population, which was also consistent with findings of Reynolds et al., in which most hospitalizations of children for neurologic complications of cat-scratch disease were caused by encephalitis or encephalopathy (30). Thus, physicians should consider catscratch disease in patients who have encephalitis or new onset hepatosplenic abnormalities, especially children.

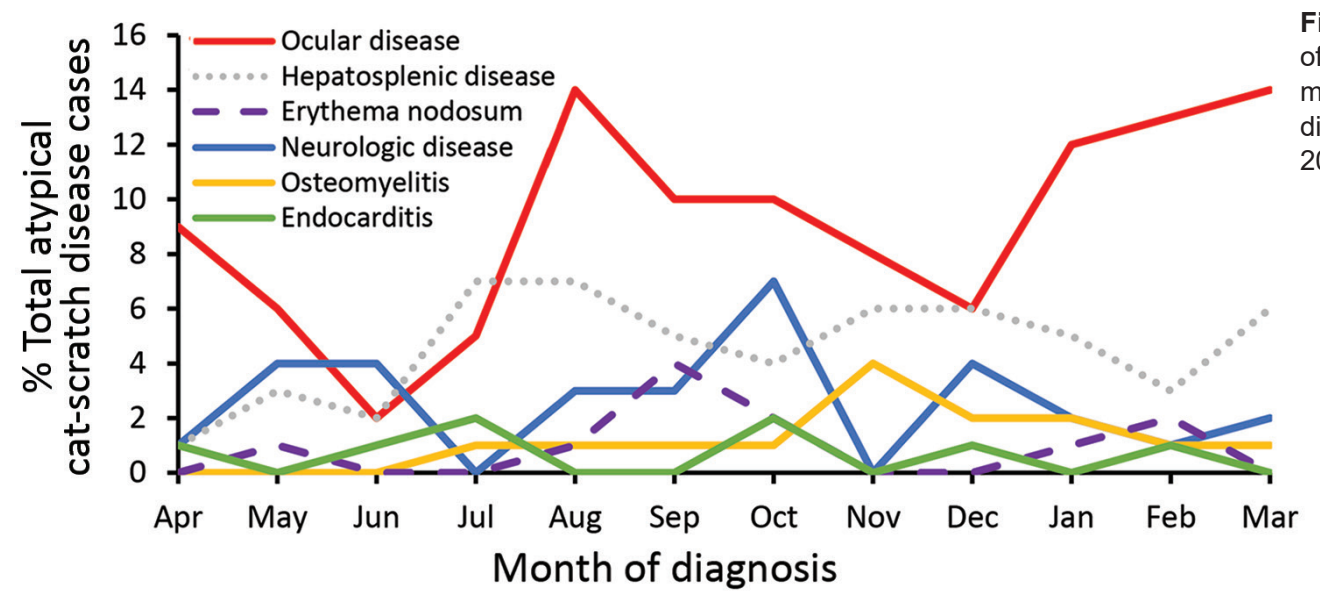

Figure 4. Seasonal variation of atypical cat-scratch disease manifestations by month of diagnosis, United States, 2005-2014. 
Table 3. Demographic characteristics for patients hospitalized with atypical cat-scratch disease and associated risk factors for hospitalization, United States, 2005-2014

\begin{tabular}{|c|c|c|c|}
\hline Characteristic & Hospitalized, no. (\%), n = 56 & Not hospitalized, no. (\%), n = 168 & Risk ratio $(95 \% \mathrm{Cl})$ \\
\hline \multicolumn{4}{|l|}{ Sex } \\
\hline M & $26(46.4)$ & $68(40.5)$ & $1.19(0.76-1.89)$ \\
\hline $\mathrm{F}$ & $30(53.6)$ & $100(59.5)$ & Referent \\
\hline \multicolumn{4}{|l|}{ Age, y } \\
\hline Child $\leq 14$ & $34(60.7)$ & $47(28.0)$ & $2.34(1.44-3.79)$ \\
\hline Younger adult, 15-49 & 19 (33.9) & 87 (51.8) & Referent \\
\hline Older adult, 50-64 & $3(5.4)$ & $34(20.2)$ & $0.45(0.14-1.44)$ \\
\hline \multicolumn{4}{|l|}{ Month of onset } \\
\hline Late summer and fall* & $32(57.1)$ & $61(36.3)$ & $1.88(1.15-3.05)$ \\
\hline January & $4(7.1)$ & $18(10.7)$ & $0.99(0.38-2.62)$ \\
\hline All other months $\dagger$ & $20(35.7)$ & $89(53.0)$ & Referent \\
\hline Residence in southern state & $36(64.3)$ & $93(55.4)$ & $1.33(0.82-2.14)$ \\
\hline Residence in rural area & $11(19.6)$ & $40(23.8)$ & $1.26(0.71-2.26)$ \\
\hline
\end{tabular}

Previous studies have documented the highest rates of cat-scratch disease in late summer and fall and a separate peak often seen in January $(13,14,29)$. One such study found that rates of $B$. henselae seropositivity among samples submitted to Mayo Clinic Laboratories over a 10 -year period were highest during September-January, with the highest annual rates in January (29). Typical cat-scratch disease diagnoses in our study followed similar seasonal patterns to those previously reported. However, atypical cat-scratch disease appeared more concentrated during August-October and January-March. The reasons for this finding are unclear but might include delays in diagnosis of atypical cat-scratch disease. For example, patients who contract cat-scratch disease and had complications during January might not be given a diagnosis of atypical cat-scratch disease at that time because they do not show classic symptoms or their symptoms take time to develop and care-seeking is delayed.

Furthermore, a recent case series of ocular manifestations of cat-scratch disease reported that 9 of 10 patients had symptoms $\leq 3$ months before showing development of ocular complications and that 3 patients had been originally given misdiagnoses of etiologies other than cat-scratch disease (31). Given that ocular manifestations of cat-scratch disease were most common in our study, increased diagnoses of atypical cat-scratch disease through March could be a sign of delayed diagnoses, particularly for manifestations that are less severe, such as those involving the eye.

Trends related to geographic distribution of cases did not differ between atypical and typical cat-scratch disease. Similar to findings from 3 previous studies that reported the highest incidences of cat-scratch disease in the southern United States $(13,14,30)$, in our study, most typical (53.0\%) and atypical (57.6\%) cat-scratch disease cases occurred in patients residing in this region. In addition, a national survey of US healthcare providers found that those in the Pacific and southern regions of the United States were more likely to have been given a diagnosis of cat-scratch disease than in other regions (32). These findings are further supported by studies that have found higher average $B$. henselae seroprevalences and active bacteremia in pet cats from warmer, more humid climates, including the southern United States $(33,34)$. Thus, healthcare providers in regions with climates that support flea abundance should be aware of the risk for cat-scratch disease and be able to recognize its atypical manifestations.

This study had several limitations. First, although MarketScan is a large database of insurance claims data from persons covered by employersponsored insurance, it is a convenience sample and may not accurately represent the characteristics of all persons in the United States. For example, trends we see in atypical cat-scratch disease by geographic region and rural residence might be biased by differences in coverage and access to care that are not accounted for here. Furthermore, MarketScan does not include data for adults $\geq 65$ years of age, military personnel, uninsured persons, or Medicaid/Medicare enrollees. These specific populations might show varying degrees of cat-scratch disease severity or risk that are not captured in our results. In addition, because only persons $<65$ years of age are included in the database, the proportion of children who have cat-scratch disease might be artificially inflated. The number of patients who had atypical catscratch disease was small, especially when broken down by manifestation. Thus, it is difficult to draw conclusions regarding risk factors for specific manifestations of atypical cat-scratch disease and hospitalization within these groups. 
Furthermore, misclassification could have occurred when ICD-9-CM codes were used to classify atypical cat-scratch disease for several reasons. ICD9-CM codes are subject to error from the clinicians and billing specialists who enter them. In addition, we excluded records that fit our criteria for manifestations of atypical cat-scratch disease but lacked additional supporting information, which could have caused us to underestimate the true burden of atypical cat-scratch disease. Last, codes for some known atypical cat-scratch disease manifestations, such as pulmonary complications and thrombocytopenia, were excluded because of etiologic ambiguity in enrollee records.

In conclusion, our findings indicate that atypical cat-scratch disease in the United States follows trends similar to those for typical cat-scratch disease but is more prevalent and severe among children $\leq 14$ years of age and is least likely to occur in older adults (50-64 years of age). In addition, differences in seasonality of diagnoses were seen, which might be an indication that diagnosis of atypical cat-scratch disease is often delayed. Ocular (retinitis/neuroretinitis and conjunctivitis) and hepatosplenic complications were the most common manifestations of atypical catscratch disease. Improved understanding of atypical cat-scratch disease might lead to better recognition of cases by clinicians, as well as inform efforts to clarify the pathophysiology of this disease.

\section{Acknowledgments}

We thank Paul Mead for serving as the third reviewer of insurance billing records of enrollees with ICD-9-CM codes in cases of discordance between the 2 reviewers and Dan Pastula for providing assistance with defining neurologic manifestations of cat-scratch disease.

\section{About the Author}

Ms. Nawrocki is an Oak Ridge Institute for Science and Education epidemiology fellow in the Bacterial Diseases Branch, Division of Vector-Borne Diseases, National Center for Emerging and Zoonotic Infectious Diseases, Centers for Disease Control and Prevention, Fort Collins, $\mathrm{CO}$. Her primary research interests include how interactions between humans, animals, and the environment facilitate the spread of infectious diseases, and the epidemiology and prevention of vector-borne diseases.

\section{References}

1. Florin TA, Zaoutis TE, Zaoutis LB. Beyond cat scratch disease: widening spectrum of Bartonella henselae infection. Pediatrics. 2008;121:e1413-25. https:/ / doi.org/10.1542/ peds.2007-1897
2. Perez C, Hummel JB, Keene BW, Maggi RG, Diniz PP, Breitschwerdt EB. Successful treatment of Bartonella henselae endocarditis in a cat. J Feline Med Surg. 2010;12:483-6. https://doi.org/10.1016/j.jfms.2009.12.018

3. Varanat M, Broadhurst J, Linder KE, Maggi RG, Breitschwerdt EB. Identification of Bartonella henselae in 2 cats with pyogranulomatous myocarditis and diaphragmatic myositis. Vet Pathol. 2012;49:608-11. https:/ / doi.org/ 10.1177/0300985811404709

4. Solano-Gallego L, Bradley J, Hegarty B, Sigmon B, Breitschwerdt E. Bartonella henselae IgG antibodies are prevalent in dogs from southeastern USA. Vet Res. 2004;35:585-95. https:// doi.org/10.1051/vetres:2004034

5. Donovan TA, Fox PR, Balakrishnan N, Ericson M, Hooker V, Breitschwerdt EB. Pyogranulomatous pancarditis with intramyocardial Bartonella henselae San Antonio 2 (BhSA2) in a dog. J Vet Intern Med. 2017;31:142-8. https://doi.org/10.1111/jvim.14609

6. MacDonald KA, Chomel BB, Kittleson MD, Kasten RW, Thomas WP, Pesavento P. A prospective study of canine infective endocarditis in northern California (1999-2001): emergence of Bartonella as a prevalent etiologic agent. J Vet Intern Med. 2004;18:56-64.

7. Pesavento PA, Chomel BB, Kasten RW, McDonald KA, Mohr FC. Pathology of Bartonella endocarditis in six dogs. Vet Pathol. 2005;42:370-3. https://doi.org/10.1354/ vp.42-3-370

8. Chen TC, Lin WR, Lu PL, Lin CY, Chen YH. Cat scratch disease from a domestic dog. J Formos Med Assoc. 2007;106(Suppl):S65-8. https:/ / doi.org/10.1016/ S0929-6646(09)60356-9

9. Chung JY, Han TH, Kim BN, Yoo YS, Lim SJ. Detection of Bartonella henselae DNA by polymerase chain reaction in a patient with cat scratch disease: a case report. J Korean Med Sci. 2005;20:888-91. https:/ / doi.org/10.3346/ jkms.2005.20.5.888

10. Keret D, Giladi M, Kletter Y, Wientroub S. Cat-scratch disease osteomyelitis from a dog scratch. J Bone Joint Surg Br. 1998;80:766-7. https://doi.org/10.1302/ 0301-620X.80B5.0800766

11. Schiellerup P, Krogfelt KA, Andersen AB. Bartonella henselae causing severe and protracted illness in an otherwise healthy person. Scand J Infect Dis. 2004;36:316-8. https://doi.org/10.1080/00365540410019516

12. Tsukahara M, Tsuneoka $\mathrm{H}$, Iino $\mathrm{H}$, Ohno $\mathrm{K}$, Murano I. Bartonella henselae infection from a dog. Lancet. 1998;352:1682. https:// doi.org/10.1016/S0140-6736 (05)61455-9

13. Jackson LA, Perkins BA, Wenger JD. Cat scratch disease in the United States: an analysis of three national databases. Am J Public Health. 1993;83:1707-11. https:/ / doi.org/ 10.2105/AJPH.83.12.1707

14. Nelson CA, Saha S, Mead PS. Cat-scratch disease in the United States, 2005-2013. Emerg Infect Dis. 2016;22:1741-6. https://doi.org/10.3201/eid2210.160115

15. Spach DH, Koehler JE. Bartonella-associated infections. Infect Dis Clin North Am. 1998;12:137-55. https:/ / doi.org/ 10.1016/S0891-5520(05)70414-1

16. Carithers HA. Cat-scratch disease. An overview based on a study of 1,200 patients. Am J Dis Child. 1985; 139:1124-33. https:// doi.org/10.1001/archpedi.1985. 02140130062031

17. Murakami $\mathrm{K}$, Tsukahara M, Tsuneoka H, Iino H, Ishida C, Tsujino K, et al. Cat scratch disease: analysis of 130 seropositive cases. J Infect Chemother. 2002;8:349-52. https:/ / doi.org/10.1007/s10156-002-0194-6 
18. Cunningham ET Jr, Koehler JE. Ocular bartonellosis. Am J Ophthalmol. 2000;130:340-9. https://doi.org/10.1016/ S0002-9394(00)00573-0

19. Amer R, Tugal-Tutkun I. Ophthalmic manifestations of Bartonella infection. Curr Opin Ophthalmol. 2017;28:607-12. https://doi.org/10.1097/ICU.0000000000000419

20. Habot-Wilner Z, Trivizki O, Goldstein M, Kesler A, Shulman S, Horowitz J, et al. Cat-scratch disease: ocular manifestations and treatment outcome. Acta Ophthalmol. 2018;96:e524-32. https://doi.org/10.1111/aos.13684

21. Carithers HA, Margileth AM. Cat-scratch disease. Acute encephalopathy and other neurologic manifestations. Am J Dis Child. 1991;145:98-101. https://doi.org/10.1001/ archpedi.1991.02160010104026

22. Marra CM. Neurologic complications of Bartonella henselae infection. Curr Opin Neurol. 1995;8:164-9. https:/ / doi.org/ 10.1097/00019052-199506000-00002

23. Arisoy ES, Correa AG, Wagner ML, Kaplan SL. Hepatosplenic cat-scratch disease in children: selected clinical features and treatment. Clin Infect Dis. 1999;28:77884. https:// doi.org/10.1086/515197

24. Anderson BE, Neuman MA. Bartonella spp. as emerging human pathogens. Clin Microbiol Rev. 1997;10:203-19. https:/ / doi.org/10.1128/CMR.10.2.203

25. Bass JW, Vincent JM, Person DA. The expanding spectrum of Bartonella infections: II. Cat-scratch disease. Pediatr Infect Dis J. 1997;16:163-79. https:// doi. org/10.1097/00006454-199702000-00002

26. Margileth AM, Wear DJ, English CK. Systemic cat scratch disease: report of 23 patients with prolonged or recurrent severe bacterial infection. J Infect Dis. 1987;155:390-402. https://doi.org/10.1093/infdis/155.3.390

27. Jacobs RF, Schutze GE. Bartonella henselae as a cause of prolonged fever and fever of unknown origin in children. Clin Infect Dis. 1998;26:80-4. https://doi.org/10.1086/516256

28. Nelson CA, Saha S, Kugeler KJ, Delorey MJ, Shankar MB, Hinckley AF, et al. Incidence of clinician-diagnosed Lyme disease, United States, 2005-2010. Emerg Infect Dis. 2015;21:1625-31. https://doi.org/10.3201/eid2109.150417

29. Theel ES, Ross T. Seasonality of Bartonella henselae IgM and IgG antibody positivity rates. J Clin Microbiol. 2019;57:e01263-19. https:/ / doi.org/10.1128/JCM.01263-19

30. Reynolds MG, Holman RC, Curns AT, O'Reilly M, McQuiston JH, Steiner CA. Epidemiology of cat-scratch disease hospitalizations among children in the United States. Pediatr Infect Dis J. 2005;24:700-4. https:/ / doi.org/ 10.1097/01.inf.0000172185.01939.fc

31. Oray M, Önal S, Koç Akbay A, Tuğal Tutkun İ. Diverse clinical signs of ocular involvement in cat scratch disease. Turk J Ophthalmol. 2017;47:9-17. https://doi.org/10.4274/tjo.28009

32. Nelson CA, Moore AR, Perea AE, Mead PS. Cat scratch disease: U.S. clinicians' experience and knowledge. Zoonoses Public Health. 2018;65:67-73. https://doi.org/10.1111/zph.12368

33. Guptill L, Wu CC, HogenEsch H, Slater LN, Glickman N, Dunham A, et al. Prevalence, risk factors, and genetic diversity of Bartonella henselae infections in pet cats in four regions of the United States. J Clin Microbiol. 2004;42:652-9. https:/ / doi.org/10.1128/JCM.42.2.652-659.2004

34. Jameson P, Greene C, Regnery R, Dryden M, Marks A, Brown J, et al. Prevalence of Bartonella henselae antibodies in pet cats throughout regions of North America. J Infect Dis. 1995;172:1145-9. https://doi.org/10.1093/infdis/172.4.1145

Address for correspondence: Courtney C. Nawrocki, Centers for Disease Control and Prevention, 3156 Rampart Rd, Fort Collins, CO 80521, USA; email: osm9@cdc.gov

\section{EID Podcast: A Worm's Eye View}

Ben Taylor, cover artist for the August 2018 issue of EID, discusses how his personal experience with the Loa loa parasite influenced this painting.

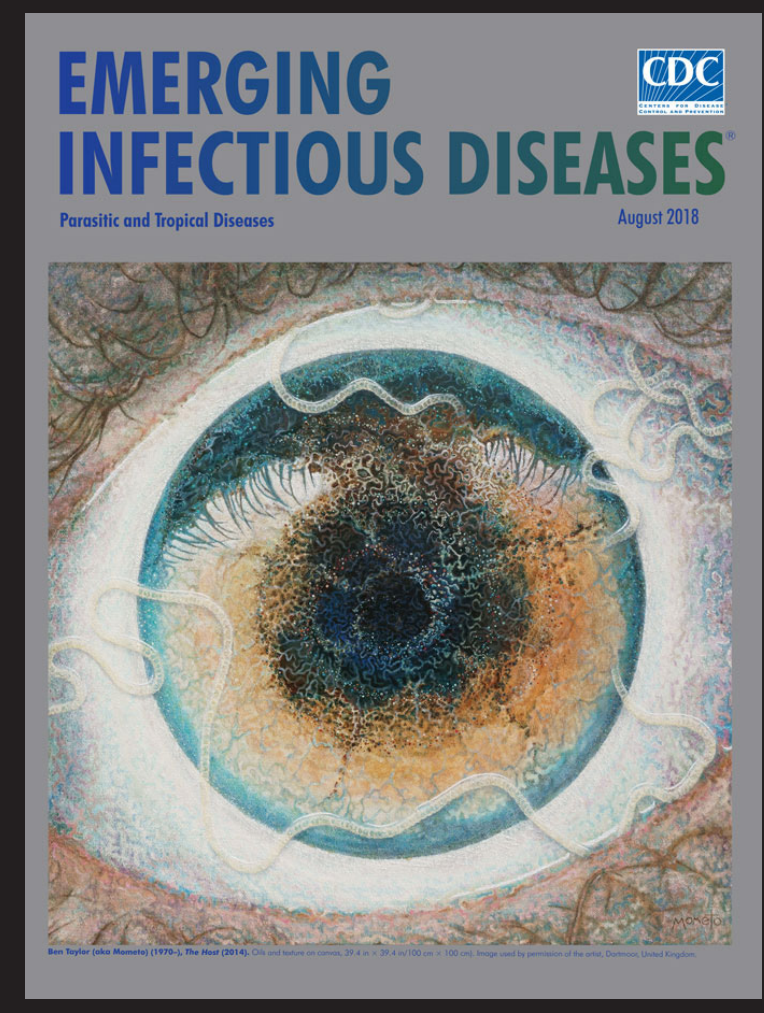

Visit our website to listen: https://tools.cdc.gov/medialibrary/ index.aspx\#/media/id/392605

EMEREING INFECTIOUS DISEASES" 